\title{
Faktor yang Memengaruhi Keberhasilan Pemberian Asi pada Bayi yang Dirawat pada Beberapa Fasilitas Kesehatan di Kota Manado
}

\author{
${ }^{1}$ Angel Deafira \\ ${ }^{2}$ Rocky Wilar \\ ${ }^{3}$ Erling D. Kaunang
}

\author{
${ }^{1}$ Program Studi Pendidikan Dokter Fakultas Kedokteran Universitas Sam Ratulangi Manado \\ ${ }^{2}$ Bagian Ilmu Kesehatan Anak Fakultas Kedokteran Universitas Sam Ratulangi \\ Email: angeldeafira@gmail.com
}

\begin{abstract}
Breast milk is the first natural food for the baby that provides all the energy and nutrients the baby needs for the first months of life. Studies show that breastfeeding is influenced by several factors, internal and external. This study was aimed to determine the factors that influence the success of breastfeeding in infants at several health facilities in Manado. This was a descriptive observational study with a cross sectional design. By using consecutive sampling method, 96 respondents were obtained according to inclusion and exclusion criteria. Data were analyzed by using SPSS 16 . The results showed several related factors to directly breastfeeding, as follows: mother age of 20-35 years old in 26 respondents (26.8\%); experience of breastfeeding in 24 respondents (24.7\%); low income in 26 respondents (26.8\%); support of health officer in 21 respondents (21.6\%); husband support in 36 respondents (37.1\%); good psychological condition of mother in 36 respondents $(37 ; 1 \%)$; good maternal knowledge of breast milk in 21 respondents $(21.6 \%)$; unemployed mother in 32 respondents $(33 \%)$; and not exposed to incessant promotion of formula milk in 27 respondents $(27.8 \%)$. Conclusion: The factors that influenced the success of breastfeeding in infants were: mother age of 20-35 years old, psychological factor of mother, maternal knowledge about breastfeeding, unemployed mother, and not exposed to the promotion of infant formula.
\end{abstract}

Keywords: breast milk, breastfeeding, postpartum mother

\begin{abstract}
Abstrak: ASI ialah makanan pertama alami bagi bayi yang menyediakan semua energi dan nutrisi yang dibutuhkan bayi untuk bulan-bulan pertama kehidupan. Berbagai studi menunjukkan pemberian ASI di pengaruhi oleh beberapa faktor, yaitu faktor internal dan eksternal. Penelitian ini bertujuan untuk mengetahui faktor yang memengaruhi keberhasilan pemberian ASI pada bayi yang dirawat di beberapa fasilitas kesehatan di Kota Manado. Jenis penelitian ialah deskriptif observasional dengan desain potong lintang. Dengan menggunakan metode consecutive sampling, didapatkan 96 responden yang sesuai dengan kriteria inklusi dan eksklusi. Data diolah dengan menggunakan SPSS 16. Hasil penelitian menunjukkan beberapa hal berkaitan dengan pemberian ASI secara langsung, yaitu: usia ibu 20-35 tahun pada 26 responden (26,8\%); adanya pengalaman menyusui pada 24 responden (24,7\%); penghasilan ibu rendah pada 26 responden $(26,8 \%)$; adanya dukungan petugas kesehatan pada 21 responden (21,6\%); adanya dukungan suami pada 36 responden $(37,1 \%)$; tidak terguncangnya faktor psikologis ibu pada 36 responden $(37,1 \%)$; pengetahuan ibu yang tinggi terhadap ASI pada 21 responden (21,6\%); ibu dengan status tidak bekerja pada 32 responden (33\%); dan ibu yang tidak terpapar gencarnya promosi susu formula pada 27 responden $(27,8 \%)$. Simpulan: Faktor- faktor yang memengaruhi keberhasilan pemberian ASI pada bayi ialah usia ibu 20-35 tahun, pengalaman menyusui, penghasilan ibu rendah, dukungan petugas kesehatan, dukungan suami, faktor psikologis ibu yang tidak terganggung, pengetahuan ibu yang tinggi tentang ASI, ibu dengan status tidak bekerja, serta ibu yang tidak terpapar oleh gencarnya promosi susu formula.
\end{abstract}

Kata kunci: ASI, faktor keberhasilan pemberian ASI, ibu pasca melahirkan 
ASI ialah makanan pertama yang alami bagi bayi yang menyediakan semua energi dan nutrisi yang dibutuhkan bayi untuk bulan-bulan pertama kehidupan, dan terus memberikan hingga setengah atau lebih kebutuhan nutrisi anak selama paruh kedua tahun, dan sampai sepertiga selama tahun kedua kehidupan. ${ }^{1}$ ASI eksklusif adalah pemberian air susu ibu pada bayi tanpa tambahan cairan lain seperti susu formula, jeruk, madu, air teh, air putih; dan tanpa tambahan makanan padat seperti pisang, papaya, bubur susu, biskuit, bubur, dan nasi tim sampai dengan usia 6 bulan. $^{2}$

Pada tahun 2012 menurut data Dinas Kesehatan Provinsi Sulawesi Utara yaitu Kota Manado hanya mendapatkan 9,59\% yaitu persentase terkecil dibandingkan dengan kabupaten/kota lain. ${ }^{3}$ Pada data yang diperoleh di Dinas Kesehatan Kota Manado tahun 2014 didapatkan jumlah bayi 8.409 yang diberikan ASI eksklusif berjumlah $1.464(18,2 \%){ }^{4}$

Berbagai studi menunjukkan pemberian ASI dipengaruhi oleh beberapa factor, yaitu faktor internal dan eksternal. Faktor internal terdiri dari usia ibu, pekerjaan ibu, pengetahuan $\mathrm{ibu}$, dan pengalaman menyusui. ${ }^{5}$ Faktor eksternal terdiri dari dukungan petugas kesehatan, dukungan suami, faktor psikologis ibu, faktor gencarnya promosi susu formula, dan penghasilan ibu. ${ }^{6,7,8}$

\section{METODE PENELITIAN}

Jenis penelitian ini ialah deskriptif observasional dengan desain potong lintang dan dilaksanakan pada Oktober 2017-Desember 2017. Pemilihan sampel dilakukan terhadap seluruh ibu normal yang baru saja melahirkan bayi normal di RSUP Prof. Dr. R. D. Kandou Manado, RS Pancaran Kasih Manado, dan Puskesmas Bahu dengan metode consecutive sampling dan didapatkan 97 responden yang memenuhi kriteria inklusi dan eksklusi. Penelitian ini menggunakan kuesioner dan data diolah menggunakan program SPSS 16.

\section{HASIL PENELITIAN}

Responden dalam penelitian ini yaitu sebanyak 97 orang yang memenuhi kriteria inklusi dan eksklusi serta telah menandatangani informed consent.

Berdasarkan hasil penelitian, dari 37 responden yang langsung memberikan ASI didapatkan responden terbanyak ialah 26 responden (26,8\%) dengan usia 20-35 tahun (Tabel 1). Dari 37 responden $(38,1 \%)$ yang langsung memberikan ASI didapatkan terbanyak 24 responden $(24,7 \%)$ yaitu ibu yang memiliki pengalaman menyusui (Tabel 2). Dari 37 responden $(38,1 \%)$ yang langsung memberikan ASI didapatkan terbanyak 26 responden $(26,8 \%)$ yaitu ibu dengan penghasilan rendah (Tabel 3).

Tabel 1. Tabulasi silang umur dengan pemberian ASI

\begin{tabular}{clcccccc}
\hline & & \multicolumn{4}{c}{ ASI } & & Total \\
\cline { 3 - 5 } \cline { 3 - 5 } & & Langsung & $\%$ & Tidak & $\%$ & & $\%$ \\
\hline Usia & $<$ 20 Tahun & 7 & $7,2 \%$ & 26 & $26,8 \%$ & 33 & $34 \%$ \\
responden & 20-35 Tahun & 26 & $26,8 \%$ & 19 & $19,6 \%$ & 45 & $46,4 \%$ \\
& $>35$ Tahun & 4 & $4,1 \%$ & 15 & $15,5 \%$ & 19 & $19,6 \%$ \\
Total & & 37 & $38,1 \%$ & 60 & $61,9 \%$ & 97 & $100 \%$ \\
\hline
\end{tabular}

Tabel 2. Tabulasi silang pengalaman menyusui dengan pemberian ASI

\begin{tabular}{|c|c|c|c|c|c|c|c|}
\hline & \multicolumn{4}{|c|}{ ASI } & \multirow[t]{2}{*}{ Total } & \multirow[b]{2}{*}{$\%$} \\
\hline & & Langsung & $\%$ & Tidak & $\%$ & & \\
\hline \multirow{2}{*}{$\begin{array}{c}\text { Pengalaman } \\
\text { menyusui }\end{array}$} & Ya & 24 & $24,7 \%$ & 37 & $38,1 \%$ & 61 & $62,9 \%$ \\
\hline & Tidak & 13 & $13,4 \%$ & 23 & $23,7 \%$ & 36 & $37,1 \%$ \\
\hline Total & & 37 & $38,1 \%$ & 60 & $61,9 \%$ & 97 & $100 \%$ \\
\hline
\end{tabular}


Tabel 3. Tabulasi silang penghasilan ibu dengan pemberian ASI

\begin{tabular}{|c|c|c|c|c|c|c|c|}
\hline & \multicolumn{4}{|c|}{ ASI } & \multirow[t]{2}{*}{ TOTAL } & \multirow[b]{2}{*}{$\%$} \\
\hline & & Langsung & $\%$ & Tidak & $\%$ & & \\
\hline \multirow[t]{5}{*}{ Penghasilan ibu } & $<\mathrm{Rp} 1.000 .000$ & 26 & $26,8 \%$ & 43 & $44,3 \%$ & 69 & $71,1 \%$ \\
\hline & $\begin{array}{l}\mathrm{Rp} 1.000 .000- \\
<\mathrm{Rp} 2.000 .000\end{array}$ & 3 & $3,1 \%$ & 7 & $7,2 \%$ & 10 & $10,3 \%$ \\
\hline & $\begin{array}{l}\operatorname{Rp} 2.000 .000- \\
<\operatorname{Rp} 3.000 .000\end{array}$ & 5 & $5,2 \%$ & 8 & $8,2 \%$ & 13 & $13,4 \%$ \\
\hline & $\begin{array}{l}\operatorname{Rp} 3.000 .000- \\
<\operatorname{Rp} 4.000 .000\end{array}$ & 2 & $2,1 \%$ & 2 & $2,1 \%$ & 4 & $4,1 \%$ \\
\hline & $\begin{array}{l}\operatorname{Rp} 4.000 .000- \\
<\operatorname{Rp} 5.000 .000\end{array}$ & 1 & $1 \%$ & 0 & $0 \%$ & 1 & $1 \%$ \\
\hline Total & & 37 & $38,1 \%$ & 60 & $61,9 \%$ & 97 & $100 \%$ \\
\hline
\end{tabular}

Dari 37 responden $(38,1 \%)$ yang langsung memberikan ASI sebanyak 21 responden $(21,6 \%)$ yaitu ibu yang mendapatkan dukungan petugas kesehatan (Tabel 4). Dari 37 responden $(38,1 \%)$ yang langsung memberikan ASI sebanyak 36 responden $(37,1 \%)$ dengan ibu yang mendapatkan dukungan suami (Tabel 5).

Berdasarkan hasil penelitian dari 37 responden $(38,1 \%)$ yang langsung memberikan ASI, sebanyak 36 responden yang langsung memberikan ASI dengan tidak terguncangnya psikologis ibu (Tabel 6).
Dari 37 responden $(38,1 \%)$ yang langsung memberikan ASI, sebanyak 21 responden $(21,6 \%)$ yaitu ibu yang memiliki pengetahuan tentang ASI tinggi (Tabel 7).

Berdasarkan hasil penelitian dari 37 responden $(38,1 \%)$ yang langsung memberikan ASI, sebanyak 32 responden (33\%) dengan ibu berstatus tidak bekerja (Tabel 8). Dari 37 responden $(38,1 \%)$ yang langsung memberikan ASI, sebanyak 27 responden $(27,8 \%)$ yang tidak terpapar gencarnya iklan susu formula (Tabel 9).

Tabel 4. Tabulasi silang dukungan petugas kesehatan dengan pemberian ASI

\begin{tabular}{ccccccccc}
\hline & & \multicolumn{3}{c}{ ASI } & \multicolumn{3}{c}{ TOTAL } \\
\cline { 3 - 5 } \cline { 5 - 6 } & & Langsung & \% & Tidak & $\%$ & & $\%$ \\
\hline Dukungan & YA & 21 & $21,6 \%$ & 41 & $42,3 \%$ & 62 & $63,9 \%$ \\
$\begin{array}{c}\text { petugas } \\
\text { kesehatan }\end{array}$ & TIDAK & 16 & $16,5 \%$ & 19 & $19,6 \%$ & 35 & $36,1 \%$ \\
Total & & 37 & $38,1 \%$ & 60 & $61,9 \%$ & 97 & $100,0 \%$ \\
\hline
\end{tabular}

Tabel 5. Tabulasi silang dukungan suami dengan pemberian ASI

\begin{tabular}{ccccccccc}
\hline & & \multicolumn{4}{c}{ ASI } & \multicolumn{2}{c}{ TOTAL } & \\
\cline { 3 - 6 } \cline { 4 - 5 } & & Langsung & \% & Tidak & $\%$ & & $\%$ \\
\hline Dukungan & YA & 36 & $37,1 \%$ & 56 & $57,7 \%$ & 92 & $94,8 \%$ \\
suami & TIDAK & 1 & $1 \%$ & 4 & $4,1 \%$ & 5 & $5,2 \%$ \\
Total & & 37 & $38,1 \%$ & 60 & $61,9 \%$ & 97 & $100 \%$ \\
\hline
\end{tabular}

Tabel 6. Tabulasi silang faktor psikologis ibu dengan pemberian ASI

\begin{tabular}{cccccccc}
\hline & & \multicolumn{4}{c}{ ASI } & TOTAL \\
\cline { 3 - 6 } & & Langsung & $\mathbf{\%}$ & Tidak & $\mathbf{\%}$ & & \% \\
\hline Faktor & YA & 1 & $1 \%$ & 3 & $3,1 \%$ & 4 & $4,1 \%$ \\
psikologi ibu & TIDAK & 36 & $37,1 \%$ & 57 & $58,8 \%$ & 93 & $95,9 \%$ \\
Total & & 37 & $38,1 \%$ & 60 & $61,9 \%$ & 97 & $100 \%$ \\
\hline
\end{tabular}


Deafira, Wilar, Kaunang: Faktor yanng memengaruhi keberhasilan ...

Tabel 7. Tabulasi silang pengetahuan ibu dengan pemberian ASI

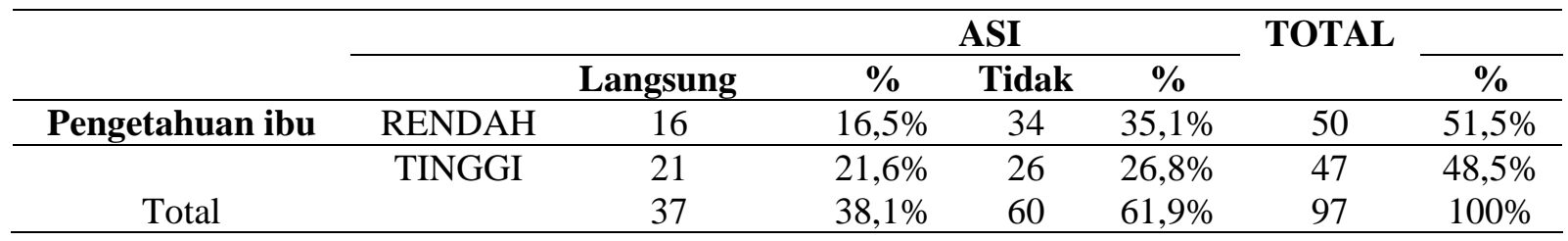

Tabel 8. Tabulasi silang pekerjaan dengan pemberian ASI

\begin{tabular}{|c|c|c|c|c|c|c|c|}
\hline & & \multicolumn{4}{|c|}{ ASI } & \multirow[t]{2}{*}{ TOTAL } & \multirow[b]{2}{*}{$\%$} \\
\hline & & Langsung & $\%$ & Tidak & $\%$ & & \\
\hline \multirow[t]{2}{*}{ Pekerjaan } & BEKERJA & 5 & $5,2 \%$ & 16 & $16,5 \%$ & 21 & $21,6 \%$ \\
\hline & $\begin{array}{c}\text { TIDAK } \\
\text { BEKERJA }\end{array}$ & 32 & $33 \%$ & 44 & $45,4 \%$ & 76 & $78,4 \%$ \\
\hline Total & & 37 & $38,1 \%$ & 60 & $61,9 \%$ & 97 & $100 \%$ \\
\hline
\end{tabular}

Tabel 9. Tabulasi silang faktor gencarnya susu formula dengan pemberian ASI

\begin{tabular}{cccccccc}
\hline & & \multicolumn{3}{c}{ ASI } & TOTAL & \\
\cline { 3 - 6 } \cline { 5 - 6 } & & Langsung & \% & Tidak & \% & & \% \\
\hline Faktor & YA & 10 & $10,3 \%$ & 17 & $17,5 \%$ & 27 & $27,8 \%$ \\
$\begin{array}{c}\text { gencarnya iklan } \\
\text { susu formula } \\
\text { Total }\end{array}$ & TIDAK & 27 & $27,8 \%$ & 43 & $44,3 \%$ & 70 & $72,2 \%$ \\
\hline
\end{tabular}

\section{BAHASAN}

Tabel 1 menunjukkan bahwa usia reponden yang banyak memberikan ASI eksklusif ialah usia 20-35 tahun. Hal ini sejalan dengan penelitian Anita $^{9}$ yang melaporkan bahwa pada ibu yang melahirkan di RSUD Wates usia 20-35 tahun lebih banyak memberikan ASI eksklusif daripada usia $>35$ tahun. Hal ini juga selaras dengan penelitian Okawary. ${ }^{10}$

Tabel 2 menunjukkan bahwa responden yang memiliki pengalaman menyusui paling banyak yang langsung memberikan ASI. Hal ini sesuai dengan penelitian Hardiani ${ }^{11}$ yang memndapatkan ibu dengan status primipara tidak lebih lancar pengeluaran ASI nya daripada multipara. Ibu dengan pengalaman menyusui lebih banyak langsung memberikan ASI kepada bayi mereka. Penelitian oleh Hastuti ${ }^{12}$ juga membuktikan bahwa terdapat hubungan antara pengalaman menyusui dan pemberian ASI eksklusif. Pengalaman menyusui memiliki hubungan yang positif antara durasi menyusui pada anak sebelumnya, terutama anak yang tepat sebelum anak yang sekarang dengan pemberian ASI pada anak saat ini. ${ }^{12}$

Tabel 3 menunjukkan bahwa responden dengan penghasilan rendah lebih banyak yang langsung memberikan ASI. Berdasarkan wawancara, banyak ibu mengatakan jika membeli susu formula maka pengeluaran akan banyak dan lebih baik memberikan ASI karena menghemat pengeluaran. Hal ini sesuai dengan penelitian oleh Arifeen ${ }^{13}$ di Bangladesh yang menyatakan pada kelompok yang mempu-nyai ekonomi rendah berpeluang lebih besar untuk memberikan ASI eksklusif karena susu formula yang mahal menye-babkan hampir sebagian besar pendapatan keluarga hanya untuk membeli susu dan tidak mencukupi kebutuhan lain dibanding ibu dengan ekonomi yang tinggi. Hal ini juga sejalan dengan penelitian oleh Afifah $^{14}$ yang menyatakan terdapat hubungan bermakna antara tingkat ekonomi dengan pemberian ASI. Ibu yang memiliki penghasilan rendah lebih banyak yang 
memberikan ASI langsung ketimbang ibu yang memiliki penghasilan tinggi.

Petugas kesehatan adalah seseorang yang dihargai, dihormati dimata klien karena mereka berstatus tinggi sesuai dengan pendidikannya. Perannya dalam kesehatan sangat dibutuhkan, untuk itu petugas kesehatan harus mampu memberikan kondisi yang dapat mempengaruhi terhadap kesehatan. Tabel 4 menunjukkan bahwa adanya dukungan petugas kesehatan yang memberikan arahan tentang IMD menjadikan ibu lebih banyak langsung memberikan ASI ketimbang tidak adanya dukungan petugas kesehatan. Hal ini sesuai dengan penelitian Mohanis ${ }^{15}$ mengenai peran petugas kesehatan dan status pekerjaan ibu dengan pemberian ASI eksklusif. Hal ini juga sesuai dengan penelitian Retnani yang membuktikan adanya hubungan antara dukungan petugas kesehatan dengan pemberian ASI. ${ }^{16}$

Bentuk dukungan yang diberikan oleh suami dapat dikelompokan menjadi 4 bentuk, yaitu: dukungan emosional, instrumental, apraisal. dan informasional. Berdasarkan penelitian wawancara oleh Shafira $^{17}$ pada ibu yang mendapatkan dukungan suami, umumnya suami memberikan motivasi dan semangat untuk istrinya agar tetap semangat menyusui secara ASI ekslusif dengan cara memberikan pujian sehingga ibu langsung memberikan ASI kepada bayi. Tabel 5 menunjukkan responden terbanyak yang memberikan ASI langsung ialah responden yang mendapatkan dukungan suami. Hal ini sejalan dengan penelitian oleh Novrianda ${ }^{18}$ yang menyatakan bahwa adanya hubungan yang bermakna antara dukungan suami terhadap pemberian ASI eksklusif.

Kondisi psikologis ibu dapat memengaruhi produksi ASI karena butuh penyesuaian pada ibu pasca melahirkan. Tabel 6 . menunjukkan ibu yang tidak memiliki gangguan psikologis akan langsung memberikan ASI pada bayinya. Hal ini sesuai dengan penelitian oleh Kamariyah ${ }^{19}$ terhadap ibu menyusui di BPS ASKI Pakis Sido Kumpul Surabaya yang menyatakan bahwa terdapat hubungan bermakna antara psikologis ibu dan pemberian ASI.

Tabel 7 memperlihatkan responden yang memiliki pengetahuan baik sangat memengaruhi pemberian ASI langsung pada bayi. Berdasarkan penelitian, ibu yang mempunyai pengetahuan tinggi lebih banyak yang langsung memberikan ASI. Hal ini sejalan dengan penelitian Prahita$\operatorname{sari}^{20}$ yang menunjukkan adanya hubungan tingkat pengetahuan ibu tentang ASI eksklusif dan perilaku pemberian ASI eksklusif secara bermakna. Pengetahuan ibu tentang ASI sangat menentukkan sikap ibu dalam pemberian ASI. Hal ini sejalan dengan penelitian oleh Handayani ${ }^{21}$ yang membuktikan adanya hubungan antara tingginya tingkat pengetahuan ibu tentang ASI dalam memengaruhi pemberian $\mathrm{ASI}^{21}$ Berdasarkan wawancara penelitian, banyak yang menyebutkan buku KIA yang menjadi sumber pengetahuan mereka tentang ASI.

Tabel 8 menunjukkan responden yang tidak bekerja lebih banyak memberikan ASI eksklusif. Penelitian yang dilakukan Kurniawan $^{22}$ membuktikan bahwa ibu yang bekerja meningkatkan frekuensi kegagalan pemberian ASI eksklusif. Penelitian yang dilakukan Ory $^{10}$ juga turut membuktikan adanya hubungan bermakna antara status pekerjaan dan pemberian ASI eksklusif, dengan hasil ibu yang tidak bekerja lebih banyak memberikan ASI eksklusif.

Tabel 9 menampilkan responden yang tidak terpapar promosi gencarnya susu formula lebih banyak yang memberikan ASI eksklusif (tanpa dicampur susu formula) dibanding yang sudah terpapar dengan promosi iklan susu formula. Penelitian oleh Rahmawati ${ }^{7}$ membuktikan semakin tidak tertarik seseorang terhadap iklan susu formula maka pemberian ASI eksklusif akan terlaksana dengan benar. Gencarnya iklan susu formula bisa memengaruhi ketertarikan ibu kepada susu formula. Hal ini juga sejalan dengan penelitian Hargono $^{24}$ yang menyatakan adanya hubungan bermakna antara pemberian ASI eksklusif dan promosi susu formula. Semakin ibu tepapar dengan promosi susu formula maka tingkat kegagalan untuk memberikan ASI semakin tinggi. 
Limitasi peneliltian ini ialah peneliti tidak meneliti hingga waktu 6 bulan, dan hanya mengambil patokan bayi baru lahir yang belum terpapar dengan MPASI.

\section{SIMPULAN}

Berdasarkan hasil penelitian dapat disimpulklan bahwa factor-faktor yang memengaruhi keberhasilan pemberian ASI pada bayi yang dirawat pada beberapa fasilitas kesehatan di Kota Manado ialah usia 20-35 tahun, adanya pengalaman menyusui, penghasilan ibu rendah, adanya dukungan petugas kesehatan dan dukungan suami, faktor psikologis ibu yang tidak terganggu, pengetahuan ibu yang tinggi tentang ASI, ibu dengan status tidak bekerja, serta ibu yang tidak terpapar oleh gencarnya promosi susu formula.

\section{SARAN}

Diharapkan hasil penelitian ini dapat dijadikan bahan pembelajaran bagi fasilitas kesehatan untuk selalu memberikan ilmu pengetahuan tetang ASI kepada ibu primigravida.

Kiranya petugas kesehatan tetap gigih dalam memberikan dukungan kepadan responden dan untuk tidak memromosikan susu formula kepada ibu

Mahasiswa diharapkan melakukan penelitian lanjut dengan mengikutsertakan analisis hubungan antar variabel dalam penelitian ini

\section{DAFTAR PUSTAKA}

1. WHO. Exclusive Breastfeeding. c2001. Available from: http://www.who.int/ nutrition/topics/exclusive_breastfeeding/e $\mathrm{n} /$

2. Departemen Kesehatan. Laporan riset kesehatan dasar. Jakarta: Kementerian Kesehatan RI, 2010.

3. Dinas kesehatan Sulawesi Utara. Data Cakupan ASI Eksklusif Sulawesi Utara. Manado,2012.

4. Riset Kesehatan Dasar(Riskesdas). 2013. Badan Penelitian dan Pengembangan Kesehatan Kementerian RI tahun 2013. 19 Oktober 2014 Available from: http://www.depkes.go.id/resources/downl oad/general/Hasil\%20Riskesdas $\% 20$ 2013.pdf.

5. Rumiasari Y. Gambaran pemberian ASI eksklusif di Puskesmas Jati Rahayu Bekasi [Skripsi]. Jakarta: Universitas Indonesia; 2012.

6. Anggorowati, Nuzulia F. Hubungan antara dukungan keluarga dengan pemberian ASI eksklusif pada bayi di Desa Bebengan Kecamatan Boja Kabupaten Kendal. Jurnal Keperawatan Maternitias. Semarang. 2013;1:1-8.

7. Arti BA, Rahmawati AN. Hubungan ketertarikan iklan susu formula dengan pemberian ASI eksklusif di Posyandu Desa Kemudo Prambanan Klaten. Klaten. Jurnal Involusi Kebidanan. 2011;1:61-72.

8. Agustaria, Fatmawati PA, Irdawati. Hubungan status ekonomi orangtua dengan pemberian ASI eksklusif pada bayi usia 0-6 bulan di Baki Sukoharjo [Skripsi]. Surakarta: Fakultas Ilmu Kesehatan Universitas Muhammadiyah Surakarta; 2013.

9. Sari CA. Hubungan umur dengan praktik pemberian ASI Eksklusif pada Ibu yang melahirkan di RSUD WATES [Skripsi]. Yogyakarta: Sekolah Tinggi Ilmu Kesehatan Jenderal Achmad Yani; 2015.

10. Okawary O. Hubungan status pekerjaan ibu dengan pemberian ASI eksklusif di wilayah kerja Puskesmas Seyegan Sleman Yogyakarta [Skripsi]. Yogyakarta: Sekolah Tinggi Ilmu Kesehatan 'Aisyiyah; 2015.

11. Hardiani SR. Status partus dan pekerjaan ibu terhadap pengeluaran ASI pada ibu menyusui 0-6 bulan. NurseLine Journal. 2017;2:44-51.

12. Hastuti WB. Hubungan pengalaman menyusui dan tingkat pendidikan ibu dengan pemberian ASI eksklusif di Kelurahan Barukan, Kecamatan Manisrenggo, Kabupaten Klaten. Jurnal Kedokteran dan Kesehatan Indonesia. 2015;6:179-87.

13. Arifeen S. Exclusive breastfeeding reduces acute respiratory infection and diarrhea deaths among infants in Dhaka slums. Pediatrics. 2001;108(4):E67.

14. Afifah E, Maulida H, Sari PD. Tingkat ekonomi dan motivasi ibu dalam pemberian ASI eksklusif pada bayi usia 0-6 bulan di bidan praktek swasta (BPS) Ummi Latifah Argomulyo, Sedayu Yogyakarta. JNKI. 2015;3:116-22. 
15. Mohanis, Widefrita. Peran petugas kesehatan dan status pekerjaan ibu dengan pemberian ASI eksklusif. Jurnal Kesehatan Masyarakat. 2014;8:40-5.

16. Retnani DA. Hubungan peran petugas kesehatan dengan motivasi ibu dalam pemberian ASI eksklusif di Desa Wonorejo Kecamatan Kencong Kabupaten Jember [Skripsi]. Jember: Universitas Jember; 2016.

17. Shafira N, Hapitria P. Hubungan antara dukungan suami dan dukungan tenaga kesehatan terhadap perilaku pemberian ASI eksklusif diwilayah daerah Puskesmas Cangkol di Kota Cirebon tahun 2017. Midwife's Research. 2017;6(1):1-22.

18. Novrianda D, Priscilla V, Suratno. Dukungan suami terhadap pemberian ASI eksklusif di wilayah kerja Puskesmas Lubuk Kilangan Kota Padang tahun 2011. Ners Jurnal Keperawatan. 2014;10:197-209.

19. Kamariyah N. Kondisi psikologi mempengaruhi produksi ASI ibu menyusui di BPS ASKI Pakis Sido Kumpul Surabaya. Jurnal Ilmiah Kesehatan. 2014;7:29-36.

20. Prahitasari E, Rahayu E D, Yanuarini A T. Hubungan pengetahuan dengan sikap ibu dalam pemberian ASI eksklusif di wilayah kerja puskesmas Pranggang kabupaten Kediri. Jurnal Ilmu Kesehatan. 2014;3:1-9.

21. Handayani L,Solikhah, Yunengsih. Hubungan pengetahuan dan teknik menyusui dengan pemberian ASI eksklusif di wilayah kerja Puskesmas Pengasih II Kabupaten Kulonprogo. Jurnal Kesmasindo. 2014;6:232-39.

22. Kurniawan B. Determinan keberhasilan pemberian air susu ibu eksklusif. Jurnal Kedokteran Brawijaya. 2013;27:236-40.

23. Hargono R, Kurniawati D. Faktor determinan yang mempengaruhi kegagalan pemberian ASI eksklusif pada bayi usia 6-12 bulan di Kelurahan Mulyorejo wilayah kerja Puskesmas Mulyorejo Surabaya. Jurnal Promkes. 2014;2:15-2 